\title{
Effects of bed-load movement on flow resistance over bed forms
}

\author{
MOHAMMAD HOSSEIN OMID ${ }^{1}$, MASOUD KARBASI ${ }^{2}$ \\ and JAVAD FARHOUDI ${ }^{1}$ \\ ${ }^{1}$ Department of Irrigation and Reclamation Engineering, University of Tehran, \\ Tehran, Iran \\ ${ }^{2}$ Department of Irrigation and Reclamation Engineering, Soil and Water Faculty, \\ University of Tehran, Tehran, Iran \\ e-mail: momid@ut.ac.ir, massoud_karbassi@yahoo.com
}

MS received 7 March 2009; revised 18 August 2010; accepted 15 October 2010

\begin{abstract}
The effect of bed-load transport on flow resistance of alluvial channels with undulated bed was experimentally investigated. The experiments were carried out in a tilting flume $250 \mathrm{~mm}$ wide and $12.5 \mathrm{~m}$ long with glass-sides of rectangular cross-section and artificial dune shaped floor that was made from Plexi-glass. Steady flow of clear as against sediment-laden water with different flow depths and velocities were studied in the experiments with a fine sand $\left(d_{50}=0.5 \mathrm{~mm}\right)$. The results indicate that the transport of fine particles $\left(d_{50}=0.5 \mathrm{~mm}\right)$ can decrease the friction factor by $22 \%$ and $24 \%$ respectively for smooth and rough beds. Increasing the bed-load size $\left(d_{50}=2.84 \mathrm{~mm}\right)$ can decrease the friction factor by $32 \%$ and $39 \%$ respectively for smooth and rough beds. The decrease in flow resistance is due to filling up of the troughs of dunes. This separation zone is responsible for increasing the flow resistance. On the upstream side of dunes condition is similar to plane bed. Presence of bed-load causes to increase the shear velocity and hence increasing flow resistance. But decreasing in flow resistance is more and it causes to decrease the total flow resistance. Grains saturated the troughs in the bed topography, effectively helping in smoothening of bed irregularities.
\end{abstract}

Keywords. Hydraulic resistance; bed forms; dune; bed-load resistance.

\section{Introduction}

In the case of steady, uniform flow in rigid boundary channels as well as in alluvial streams, there is a definite relationship between the mean velocity of flow $U$, the hydraulic radius $R$, the energy gradient $S_{f}$ and the characteristics of the flow boundary. Such a relationship is commonly known as a resistance equation. The form of these equations and the constants involved in them can be taken to be well established for subcritical flow in rigid boundary open channels. However, considerable uncertainty prevails over the choice of the proper value of the coefficients and constants involved in resistance equations for alluvial-channel flows. 
In recent years, much progress has been made towards the understanding of the processes at work in alluvial rivers. A synthesis of these processes is often presented in the form of trinity placing turbulent flow, sediment transport, and bed form development as the three controlling parameters. More importantly, the trinity identifies the complex system of feedback relationships by which the parameters interact. These relationships are still poorly understood. For example, although there exists a considerable body of knowledge describing the effect of flow velocity and turbulence on the initial motion and transport of sediment, there is a lack of information concerning the feedback effect of sediment transport on flow characteristics.

Most of the information concerning the feedback effect of sediment transport on flow characteristics relates to the case of suspended sediment. In these case studies it has been demonstrated that the introduction of suspended sediment in a clear flow may either amplify or damp turbulence, depending on the relative magnitude of flow variables (flow velocity, density and turbulence-length scale) and sediment transport variables (particle size, density, velocity, and concentration) (Pullaiah 1978; Arora 1986; Khullar et al 2002).

Although much less research has been done concerning the feedback effect of bed-load transport on flow characteristics, the generally accepted view is that bed-load extracts momentum from the flow, bringing about which causes a reduction of near-bed velocity and an increase of roughness length in proportions that are dependent on related to the thickness of the moving sediment layer (Owen 1964; Smith \& McLean 1977; Dietrich 1982; Grant \& Madsen 1982; Dyer 1986; Wiberg \& Rubin 1989; Jiang 1995; Song et al 1998; Bergeron \& Carbonneau 1999, 2000; Yoon 2000; Peng Gao \& Abrahams 2004; Campbell et al 2005). Wiberg \& Rubin (1989) used the term bed-load roughness to describe the increase in roughness length attributed to bed-load transport. However, Heathershaw \& Langhorne (1988) observed that seabed roughness length actually decreased during intense bed-load movement while it remained unaffected by weaker bed-load movements. This latter result corroborates those of Whiting \& Dietrich (1990), suggesting that the roughness of mobile alluvial beds remains unaffected by particles moving on the bed.

When the shear stress exceeds to a certain stage, bed forms begin to develop. This bed forms cause to increase flow resistance by separation of the flow behind them. There are many investigations on determining the flow resistance that caused by these bed forms. But in all these investigations, the effect of bed-load transport has not been accounted for.

In the present research work, experimental data have been employed to investigate the effect of bed-load movement on flow resistance in the presence of dune shaped bed forms.

\section{Experimental set-up}

Experiments were performed in a tilting channel of glass sides and smooth bed made of Perspex, and of rectangular cross-section $250 \mathrm{~mm}$ wide and $12.5 \mathrm{~m}$ long. The downstream end of the channel is provided with a sediment trap with a collecting basket, the weight of sediments collected in the basket being continuously recorded through a digital weighing scale. Downstream of the sediment trap is a tailgate consisting of a set of horizontal rotating flaps to provide various degrees of opening for the water to flow through. The tailgate is used to adjust the depth of water in the channel without causing undue backwater effects in to the channel. In each of the experiments, clear water is supplied at a steady rate from an overhead constant head tank. For experiments with the rough bed, a single layer of uniform sand with a $D_{50}$ of $0.5 \mathrm{~mm}$ was glued onto the Perspex bed. The same size of sand was employed in the experiments with bed load. Velocities of flow were measured by a $10 \mathrm{~mm}$ propeller current meter (figure 1). 


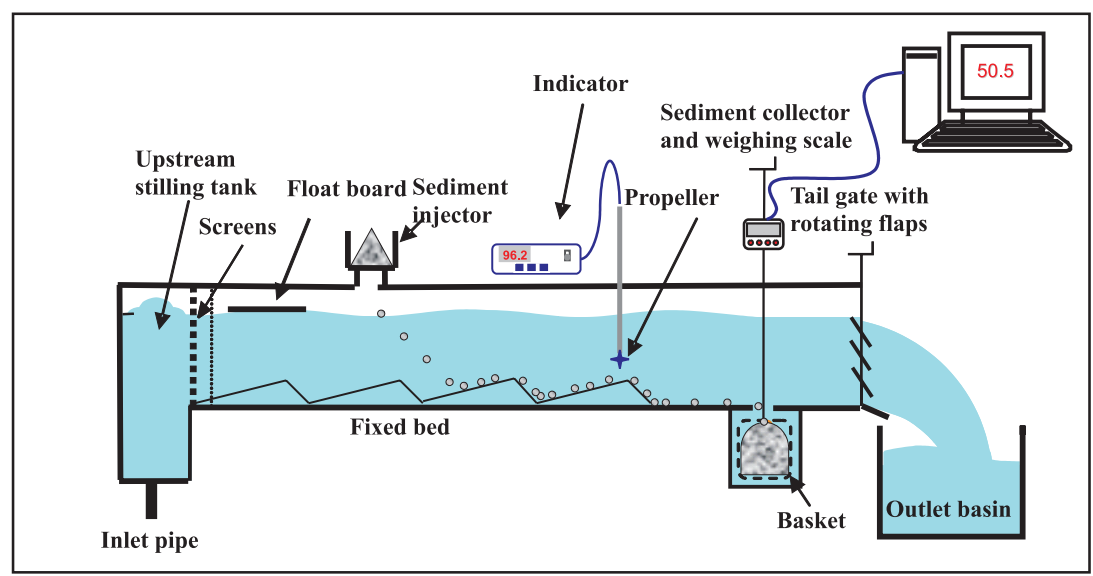

Figure 1. Experimental set-up.

Due to difficulties from freezing self formed bed forms and the fact that particles do not move over frozen bed forms (because the surface of the bed forms was sticky and therefore particles could not move over it), we have chosen the artificial bed forms to investigate the effects of sediment transport on flow resistance.

The artificial bed forms were made by using $8 \mathrm{~mm}$ thick Perspex. Geometrical properties of bedforms have been studied by Yalin (1964). By making some experimentally unsupported assumption, dimensionless variables for height $\Delta$ and length $\lambda$ of bedforms were derived, and the functional relations were obtained from experimental data. The height $\Delta$ was shown to be related to the shear stress, the latter depending on the flow depth. A dimensionless expression for the bedform height was given by

$$
\frac{\Delta}{h}=f c t 1\left(\frac{\tau_{0}}{\left(\tau_{0}\right)_{c r}}\right)=f c t 2\left(\frac{h}{h_{c r}}\right),
$$

where, $h_{c r}$ is the depth at which incipient motion takes place. Yalin (1964) obtained

$$
\frac{\Delta}{h}=\frac{1}{6}\left(1-\frac{h_{c r}}{h}\right) \text {. }
$$

Since $h_{c r}<h$, it was concluded that the height $\Delta$ cannot exceed one-sixth of the flow depth, or

$$
\frac{\Delta}{h}<\frac{1}{6} \text {. }
$$

Nordin et al (1965) suggested that a value of $1 / 3$ instead $1 / 6$ is better.

Again applying dimensional reasoning, Yalin (1964) showed that the length $\lambda$ of bedforms is given by

$$
\frac{\lambda}{h}=f c t\left(\frac{\bar{h}}{d}\right),
$$

for large-particle Reynolds numbers $u_{*} d / v$, and

$$
\frac{\lambda}{d}=\text { const. }
$$


For small-particle Reynolds numbers, plotting the experimental data, previous equations could be rewritten as

$$
\frac{\lambda}{h}=5
$$

For $d \geq 0.38 \mathrm{~mm}$, and

$$
\frac{\lambda}{d}=1000
$$

for $d \leq 0.18 \mathrm{~mm}(\operatorname{Graf}(1971))$.

Because our grains $(0.5$ and $2.84 \mathrm{~mm})$ were larger than $0.38 \mathrm{~mm}$, we used equation (6) for bedform length. There are many other relationships for alluvial bedforms length and height in the literature e.g. Karim (1999), Julien \& Klaassen (1995), Van Rijn (1984), Allen (1978), Ranga Raju \& Soni (1976) and Yalin (1964).

We used Graf $(1971,1998)$ recommended criteria for our experimental work.

With respect to the average conditions $(24 \mathrm{~cm})$ bed form properties are determined as follows:

$$
\Delta=4 \mathrm{~cm} \quad \text { and } \quad \lambda=118 \mathrm{~cm} .
$$

This artificial geometry was slightly modified, when sediment was deposited downstream of the crest.

Various slopes of the channel and velocities of flow were considered in these experiments. Prior to the experiments with sediment-laden flow, for a given slope of the channel and discharge of water, a uniform flow (without sediments) was first obtained by adjusting the tailgate to attain a prescribed depth. Different concentrations of sediments were then injected into the flow at constant rate using a screw feeder system at the upstream end of the flume. The rate of sediment supply was kept constant by adjusting the feeder to keep the sand level matching with the top level of the container. Flow measurements were made for various injection rates, less than the rate at which initiation of sediment deposition on the bed was observed. Bed-load particles were collected in the sediment trap provided at the downstream end of the flume to be collected and discarded periodically. For each injection rate $(I)(\mathrm{Kg} / \mathrm{sec})$ expressed in terms of mass rate, the corresponding volumetric concentration of sediment $C$ is simply

$$
C=\frac{I}{Q \cdot \rho_{s}}
$$

where $Q$ is the water discharge $\left(\mathrm{m}^{3} / \mathrm{sec}\right)$ and $\rho_{s}$ is sediment density, taken to be $2650 \mathrm{~kg} / \mathrm{m}^{3}$. The experimental conditions are summarized as follows:

The experiments were carried out with (i) clear water over smooth and rough beds, and (ii) sediment laden flows over smooth and rough beds. Various slopes of the channel as well as various velocities of flow were taken into account. This information was then used to set the depth of flow before injecting sediment at the upstream end in the second series of experiments.

The experimental conditions are summarized as mentioned below.

(i) Sediment diameter: $0.5 \mathrm{~mm}, 2.84 \mathrm{~mm}$; (ii) sediment concentration: 0.0025-0.0065; (iii) water depth: 53 to $310 \mathrm{~mm}$; (iv) mean velocity: 0.22 to $1 \mathrm{~m} / \mathrm{s}$; (v) bed slopes: 1:1000, 2:1000, 3:1000 and 5:1000. 
For each run the velocity profiles were obtained for 6 to 7 sections of the different parts of the fifth bed form. Velocity profiles were obtained for layers starting from $10 \mathrm{~mm}$ above the bed, which was dictated by current meter propeller. Velocities were recorded at vertical intervals of $5 \mathrm{~mm}$ when near the bed and at higher intervals when towards the water surface.

Friction factor was determined by using energy line slope as follows:

$$
f=\frac{8 R_{b} g S_{f}}{V^{2}}
$$

where $R_{b}$ is the hydraulic radius with elimination of sidewall effects, $g$ is acceleration due to gravity, $S_{f}$ is energy line slope, and $V$ is the average flow velocity. $S_{f}$ was determined by measuring water surface at different sections of channel. The formula is used to eliminate side wall effects on flow resistance Vanoni \& Brooks (1957).

\section{Results}

\subsection{Friction factor}

In alluvial channels, friction factor can be expressed into four components: (i) grain roughness, (ii) form roughness, (iii) suspended load roughness, (iv) bedload roughness. Because of the suspended load being absent, the remaining three factors are considered in the experiments.

Figure 2 shows the results of the smooth bed experiments with clear water. In this figure, friction factor is plotted against the relative depth $\left(\frac{h}{\Delta}\right)$. A comparison of these results with Shen et al (1990) and Van Rijn (1984) equations indicates that they are in good agreement with Shen equation. It should be noted that Shen equation presents only the form resistance, where as the results of the present study indicate a sum of the form and skin frictions. It can be seen from figure 2 that $73 \%$ of the resistance is due to form resistance while the remaining $27 \%$ due to skin resistance. In addition, a comparison between these results and results of

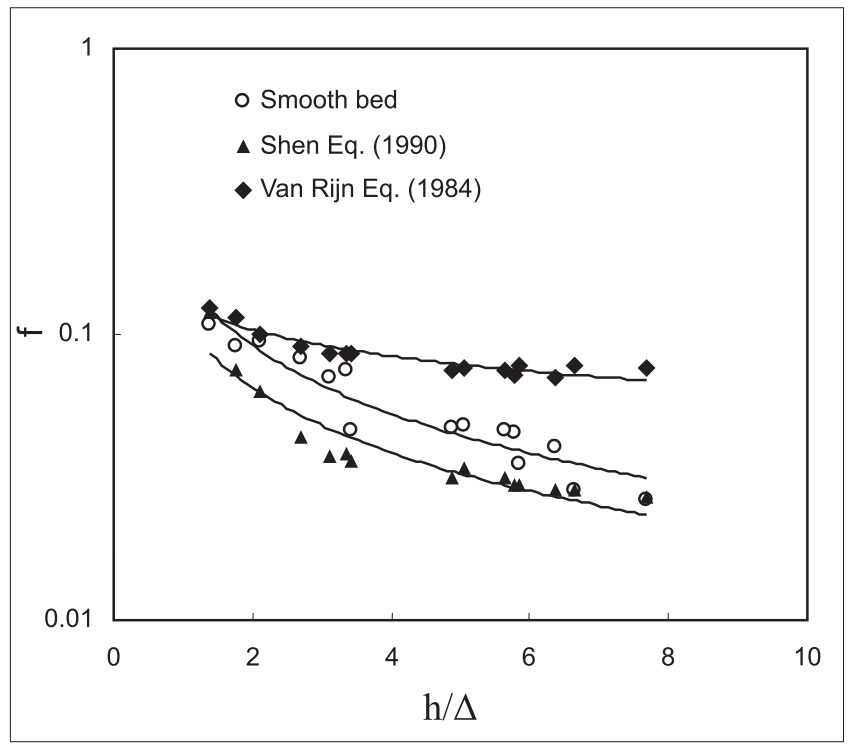

Figure 2. A comparison between experimental results of Shen et al (1990) and Van Rijn (1984) equations. 


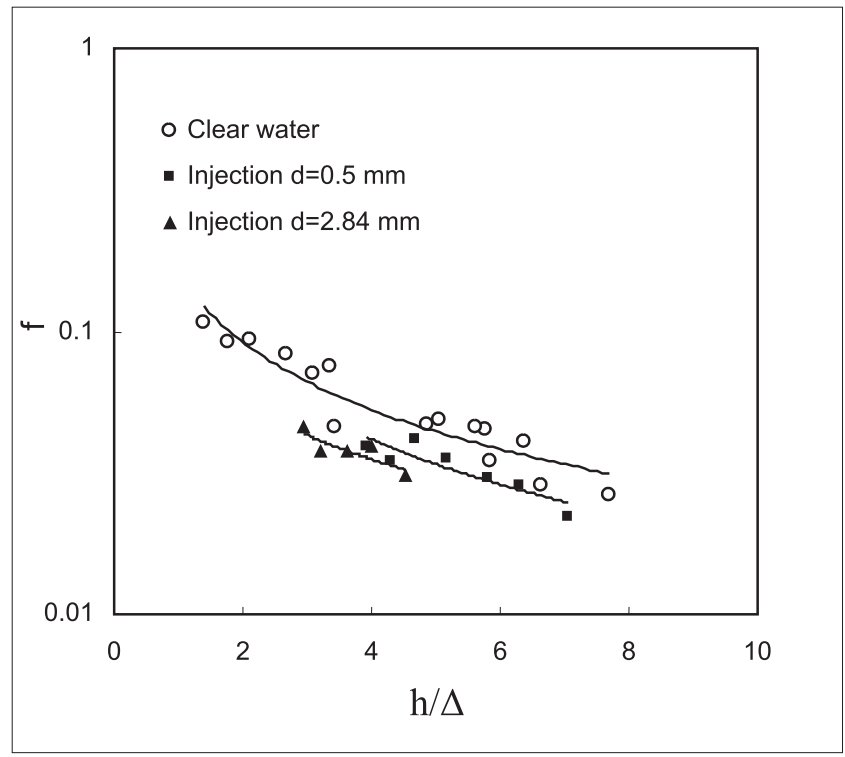

Figure 3. A comparison between clear water flow friction factor and friction factor in sediment carrying flow on smooth bed.

Omid et al (2003) for plane bed indicates that $70 \%$ of the resistance is due to form, while the remaining $30 \%$ due to skin resistance. This is well in agreement with the preceding conclusion as about equation of Shen.

Figure 3 shows the results of the experiments in which bed-load $\left(d_{50}=0.5,2.84 \mathrm{~mm}\right)$ was injected in to the flow over smooth bed. Because of sedimentation and development of new bed forms, these series of experiments were performed at higher discharge levels $(Q>25 \mathrm{lit} / \mathrm{sec})$. It can be observed that presence of bed-load $\left(d_{50}=0.5 \mathrm{~mm}\right)$ can reduce the friction factor as compared to clear water flow by $22 \%$. Injection of coarse sediment $\left(d_{50}=2.84 \mathrm{~mm}\right)$ reduces the friction factor at a higher rate compared to when $0.5 \mathrm{~mm}$ sediment is injected, the rate the reduction being $32 \%$. It should be noted that, coarse material experiments were performed at a higher slope $(S=0 \cdot 005)$.

Figure 4 shows the results of the experiments in which bed-load $\left(d_{50}=0.5,2.84 \mathrm{~mm}\right)$ was injected in to the flow, over rough bed surface. It is evidently shown that presence of bed-load $\left(d_{50}=0.5 \mathrm{~mm}\right)$ can reduce the friction factor as compared to clear water flow (by $24 \%)$. Injection of coarse sediment $\left(d_{50}=2.84 \mathrm{~mm}\right)$ can reduce the friction factor more in comparison with the case of $0.5 \mathrm{~mm}$ sediment injection, the rate of reduction is $39 \%$. It should be noted that, coarse material experiments were performed at a higher slope $(S=0.005)$.

\subsection{Velocity distribution}

For the purpose of a comparison between velocity profiles for clear water flow and sediment injected flow, measurement of velocity profiles were performed at the central part of the flume and at four different sections (figure 5). In figures 5 to 8 the velocity profiles for different conditions are presented. These results show a good agreement with the trend of decrease in flow resistance. The higher the flow resistances, the lower are the velocities. Sediment transport affects the near bed velocity distribution at smooth bed experiments. In all sections near bed, the magnitudes of velocities increase. Near the surface of the water, the magnitudes of velocities do not change or decrease (figures $5 \mathrm{a}-\mathrm{d}$ ). It is due to effects of moving particles, and this effect decreases as $y$ increases. 


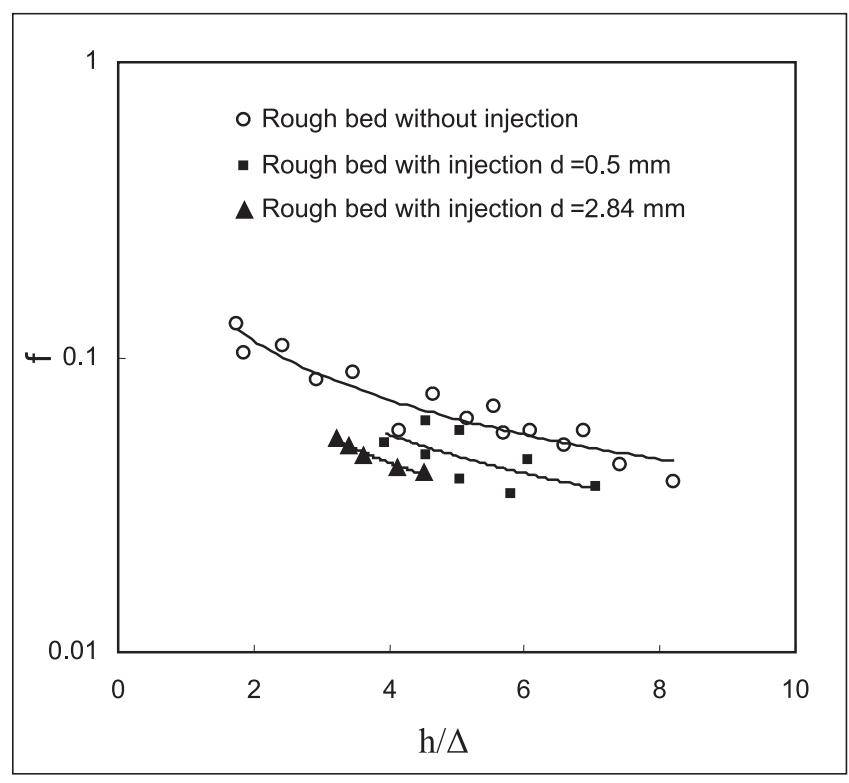

Figure 4. A comparison between clear water flow friction factor and friction factor when injected in to flow, on a rough bed.

Figure 6 shows the velocity distributions over rough bed. The mechanism is same as smooth bed but the effect of sediment transport is more drastic.

Figure 6 shows the effect of sediment transport on velocity distributions over smooth bed and median particle size of $2.84 \mathrm{~mm}$. It can be seen that not only near the bed velocity magnitudes increase, but also near surface velocity magnitudes. In figure 8 the pattern is similar to figure 7, but the effect is more drastic.

The results of velocity distributions with clear water (over smooth and rough beds) and sediment-laden (over smooth and rough beds) flows are consistent with the results of friction factors. The higher is the friction factors, the lower is the velocity magnitudes.
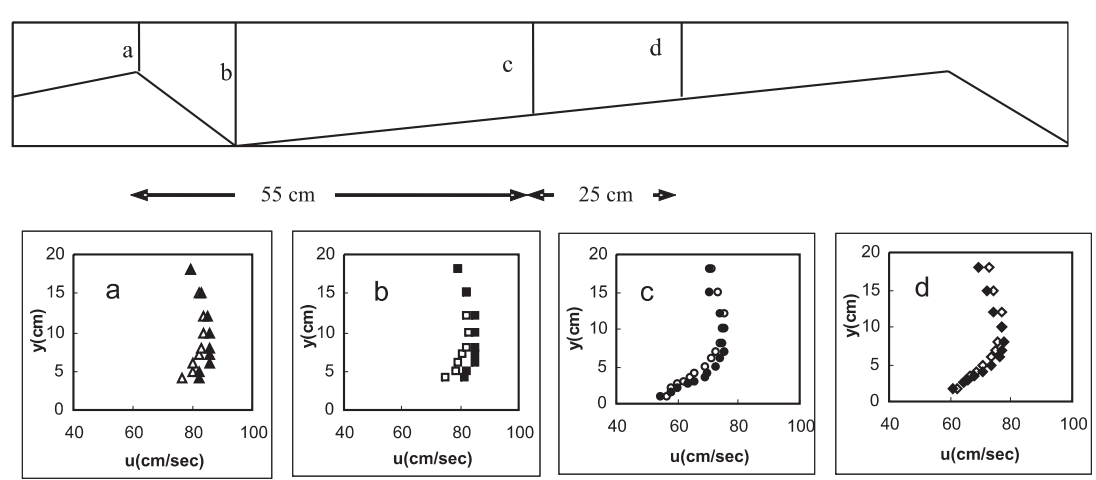

Figure 5. Effect of sediment transport on velocity profiles over a smooth dune (solid dotes indicates sediment laden flows and hollow dotes indicate clear water) $\left(d_{50}=0.5 \mathrm{~mm}\right), Q=36.07 \mathrm{lit} / \mathrm{s}$, $S=0.002, h=0.216 \mathrm{~m}$, smooth bed $C=0.0047$. 

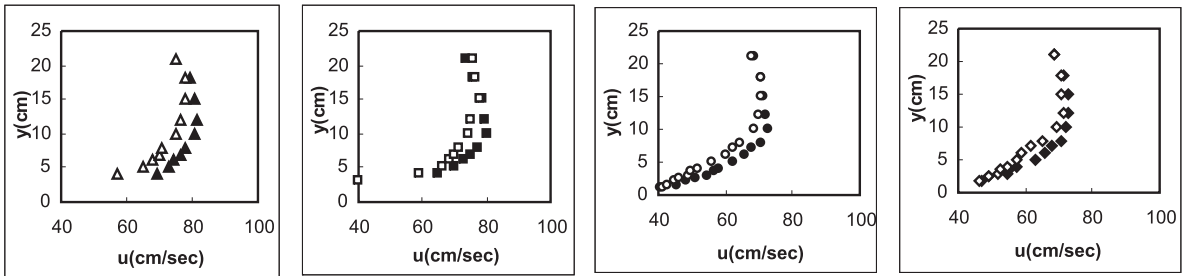

Figure 6. Effect of sediment transport on velocity profiles over a rough dune $\left(d_{50}=0.5 \mathrm{~mm}\right)$ $Q=37.05 \mathrm{lit} / \mathrm{s}, S=0.002, h=0.2305$, rough bed $C=0.0037$.
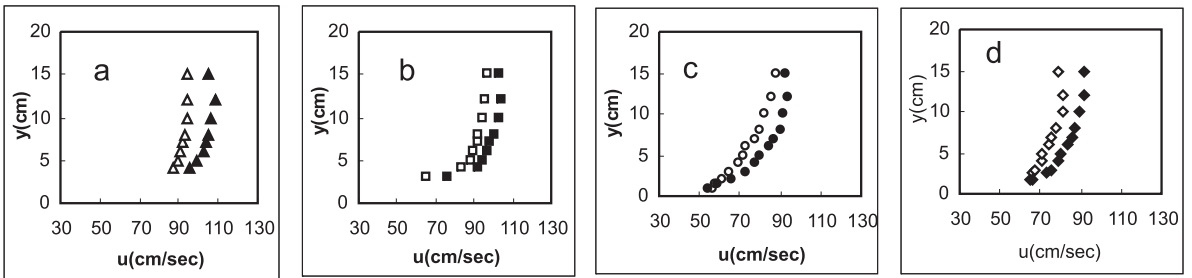

Figure 7. Effect of sediment transport on velocity profiles over a smooth dune $\left(d_{50}=2.84 \mathrm{~mm}\right)$ $Q=33.2 \mathrm{lit} / \mathrm{s}, S=0.005, h_{c}=0.175, h_{s}=0.16 \mathrm{~m}$, smooth bed $C=0.0065$.

\subsection{Effect of sediment transport on bed topography}

In the experiments involving sediment transport the lee slope of the dunes was modified for different conditions, the modification being varied for different experiment series. Figure 9 presents the slope modifications for the different conditions.

According to figure 9 (at both gradations) the slope of the lee side is more for smooth bed experiments, so the flow resistance is more at these bed experiments. Flow resistance analysis shows that decrease in flow resistance is more for rough bed experiments.

\subsection{Effect of sediment concentration on flow resistance}

A summary of the effect of sediment concentration on the friction factor (for rough and smooth beds) is presented in figure 10. This figure shows that concentration has no significant effect on flow resistance. It should be noted that deposition begins at high concentrations with other bed forms beginning to develop.
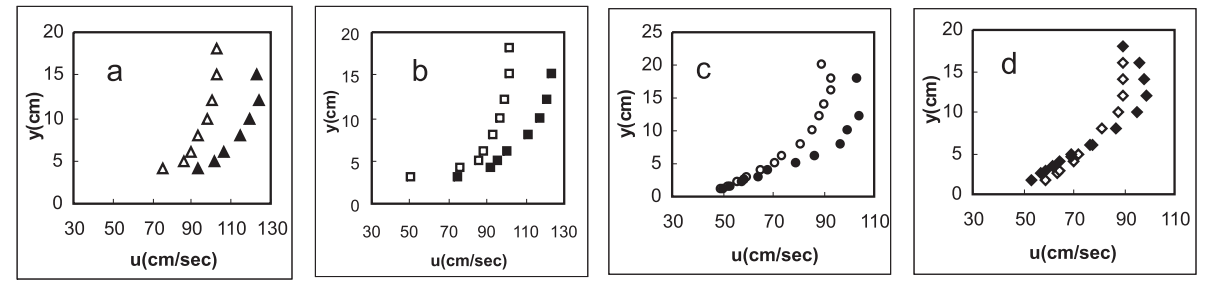

Figure 8. Effect of sediment transport on velocity profiles over a rough dune $\left(d_{50}=2.84 \mathrm{~mm}\right)$ $Q=38.36$ lit $/ \mathrm{s}, S=0.005, h_{c}=0.195, h_{s}=0.175 \mathrm{~m}$, rough bed $C=0.0065$. 

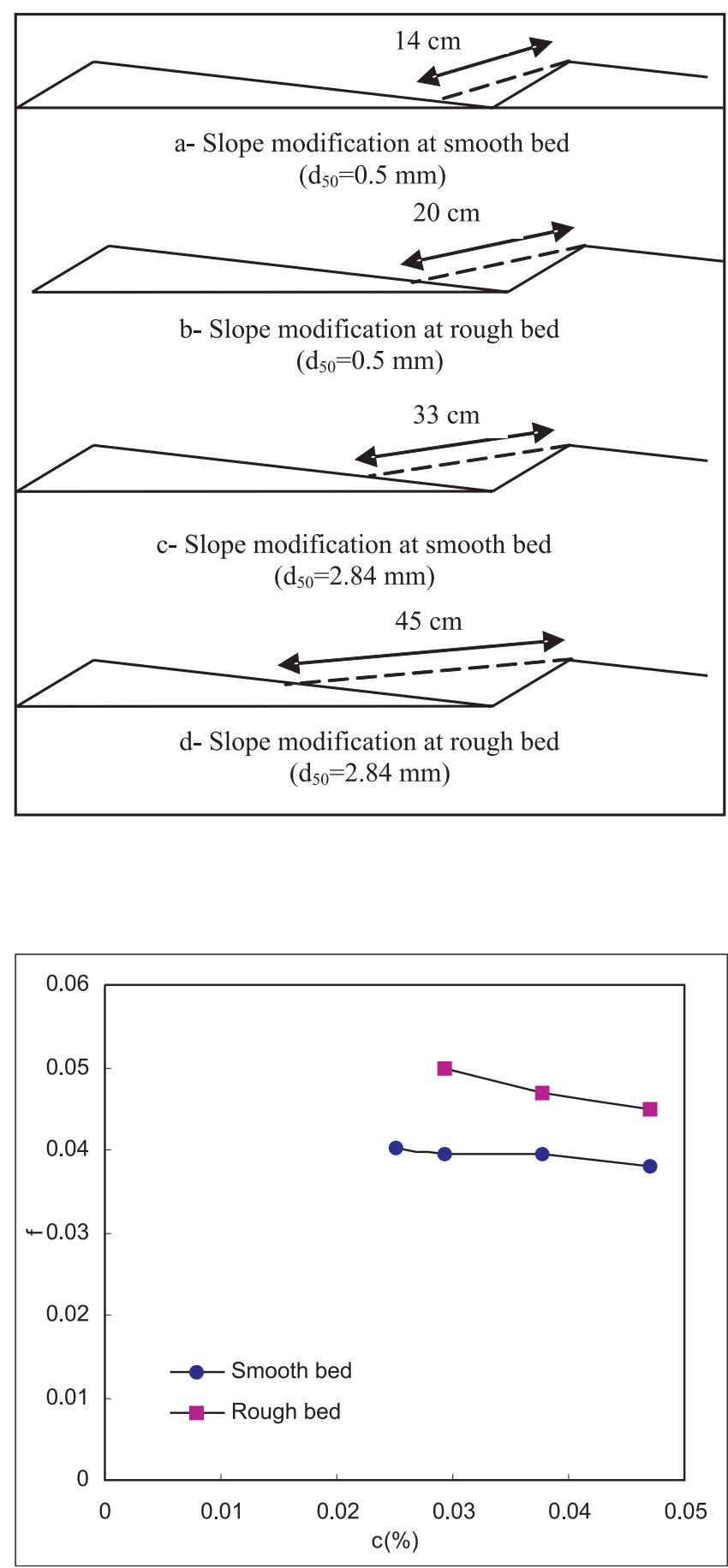

Figure 9. Slope modification at different conditions.

Figure 10. Effect of sediment concentration on flow resistance. 


\section{Conclusions}

The following results can be concluded from the present investigation: movement of sediment particle over artificial dunes decreases the flow resistance. Transport of fine particles $\left(d_{50}=\right.$ $0.5 \mathrm{~mm}$ ) can decrease the friction factor by $22 \%$ and $24 \%$ respectively for smooth and rough beds. Increasing the bed-load size $\left(d_{50}=2.84 \mathrm{~mm}\right)$ can decrease the friction factor by $32 \%$ and $39 \%$ for smooth and rough beds respectively.

The decrease in flow resistance over rough bed is more than on smooth bed. Increase in bed material size decreases flow resistance in comparison with finer materials. This decrease can be attributed to a reduction to eddy turbulence downstream of dune crest due to entrainment of grains to eddy nucleus as well as decrease at the lee side slope of the dunes. Grains filled the troughs in the bed topography, effectively causing bed irregularities to be smoothed out.

\section{References}

Allen J 1978 Computational methods for dune time-lag: Calculations using Stein's rule for dune height. Sedimentary Geol. 20(3): 165-216

Arora A, Raju K, Gadre R 1986 Resistance to flow and velocity distribution in rigid boundary channels carrying sediment-laden flow. Water Resources Res. 22(6): 943-951

Bergeron N, Carbnneau P 1999 The effect of sediment concentration on bed load roughness. J. Hydrological Processes 13(16): 2583-2589

Campbell L 2005 Bed-load effects on hydrodynamics of rough-bed open-channel flows. J. Hydraulic Eng. ASCE 131(7): 576-585

Carbnneau P, Bergeron N 2000 The effect of bedload transport on mean and turbulent flow properties. J. Geomorphology 35(3,4): 267-278

Dietrich W 1982 Flow, boundary shear stress, and sediment transport in a river meander. PhD thesis, Univ. of Washington, Seattle

Dyer K 1986 Coastal and estuarine sediment dynamics (New York: Wiley Interscience)

Graf W 1971 Hydraulics of sediment transport. McGraw-Hill Series In: Water Resource and Environmental Engineering

Graf W 1998 Fluvial Hydraulics: Flow and transport processes in channels of simple geometry, John Wiley \& Sons

Grant W, Madsen O 1982 Movable bed roughness in oscillatory flow. J. Geophys. Res. 87: 469-481

Heathershaw A, Langhorne D 1988 Observations of nearbed velocity profiles and seabed roughness in tidal currents flowing over sandy gravels. Estuarine, Coast. Shelf Sci. 26: 459-482

Jiang Z 1995 The motion of sediment-water mixtures during intense bedload transport: computer simulations. Sedimentol. 42: 935-945

Julien P, Klaassen G 1995 Sand-dune geometry of large rivers during floods. J. Hydr. Eng. ASCE 121(9): 657-663

Karim F 1999 Bed form geometry. J. Hydr. Eng. ASCE 125(12): 1253-1261

Khullar N, Kothyari U, Ranga Raju K 2002 The effect of suspended sediment on flow resistance. $5^{\text {th }}$ International conference on hydro-science and engineering, September, 18-21, Warsaw, Poland

Omid M, Madhavi A, Narayanan R 2003 Effect of bed load transport on flow resistance in rigid boundary channels. XXX IAHR Congress, Thessaloniki, Greece

Owen P 1964 Saltation of uniform grains in air. J. Fluid Mech. 20: 225-242

Pen Gao, Abrahams A 2004 Bed load transport resistance in rough open channel flows. Earth Surface Processes and Landforms 29: 423-435

Pullaiah V 1978 Transport of fine suspended sediment in smooth bed channels. PhD thesis, University of Roorkee, Roorkee

Ranga Raju K, Soni J 1976 Geometry of ripples and dunes in alluvial channels. J. Hydr. Res. Delft, the Netherlands, 14(3) 
Shen H, Fehlam H, Mendoza C 1990 Bed form resistance in open channel flows. J. Hydraulic Eng. ASCE 116(6): 799-815

Smith J, McLean S 1977 Spatially averaged flow over a wavy surface. J. Geophys. Res. 82: 1735-1746 Song, Chiew Y, Chinc 1998 Effect of bed-load movement on flow friction factor. J. Hydraulic. Eng. 124: $165-175$

Van Rijn L 1984 Sediment transport, Part III: Bed forms and alluvial roughness. J. Hydr. Eng. ASCE 110(12): 1733-1754

Vanoni V, Brooks N 1957 Laboratory studies of the roughness and suspended load of alluvial streams. Sedimentation Laboratory, California Institute of Technology, Pasadena, California

Whiting P, Dietrich W 1990 Boundary shear stress and roughness over mobile alluvial beds. J. Hydraul Eng. 116: 1495-1511

Wiberg P, Rubin D 1989 Bed roughness produced by saltating sediment. J. Geophysics. Res. 94: 5011-5016

Yalin M 1964 Geometrical properties of sand waves. J. Hydr. Div. ASCE 90(5):

Yoon B, Yu K, Muste M, Kruger A, Ettema R 2000 Bed-shear stress distribution in open-channel flow with sediment transport. $4^{\text {th }}$ International conference on hydro-science and engineering, Seoul, South Korea 